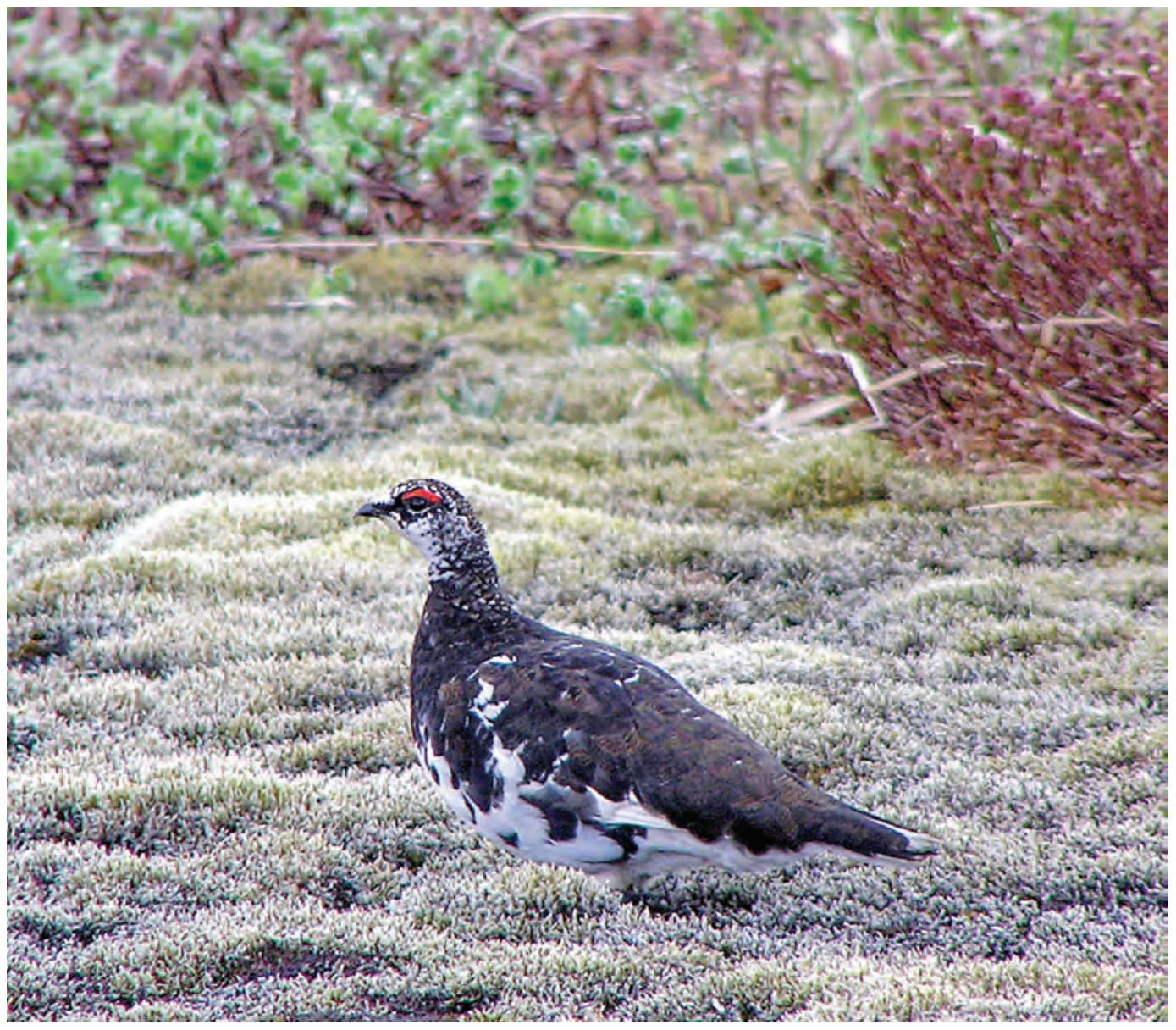

FRONTISPIECE. Evermann's Rock Ptarmigan (Lagopus muta evermanni), endemic to the Near Islands in the western Aleutians, were reintroduced to Agattu from Attu to reestablish a breeding population. Translocations during 2003-2006 were successful as translocated birds survived, nested, and produced young which survived until recruitment in successive breeding seasons. Photograph of a male during the breeding period by Steve E. Ebbert. 


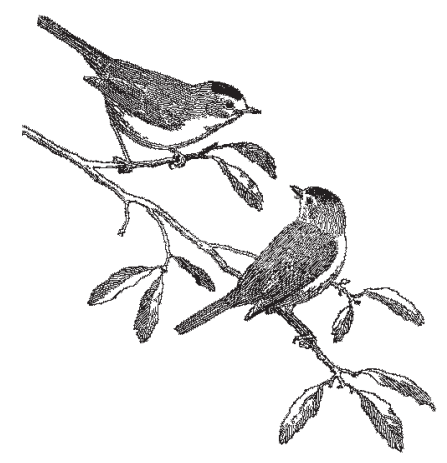

\title{
The Wilson Journal of Ornithology
}

Published by the Wilson Ornithological Society

VOL. 122, NO. 1

March 2010

PAGES 1-206

The Wilson Journal of Ornithology 122(1):1-14, 2010

\section{DEMOGRAPHY OF A REINTRODUCED POPULATION OF EVERMANN'S ROCK PTARMIGAN IN THE ALEUTIAN ISLANDS}

\author{
ROBB S. A. KALER, ${ }^{1}$ STEVE E. EBBERT, ${ }^{2}$ \\ CLAIT E. BRAUN, ${ }^{3}$ AND BRETT K. SANDERCOCK ${ }^{1,4}$
}

\begin{abstract}
We report results of a 4-year translocation effort to reestablish a breeding population of Evermann's Rock Ptarmigan (Lagopus muta evermanni) in the Near Islands group of the western Aleutian Archipelago. Habitat restoration was completed by eradication of introduced foxes from Agattu Island by 1979. We captured and moved 75 ptarmigan from Attu Island to Agattu Island during 2003-2006, and monitored 29 radio-marked females in the last 2 years of the study. We compared the demography of newly translocated birds $(n=13)$ with resident birds established from translocations in previous years $(n=16)$. Mortality risk was increased by translocation and $15 \%$ of females died within 2 weeks of release at Agattu Island. All surviving females attempted to nest but initiated clutches 8 days later in the breeding season and laid 1.5 fewer eggs per clutch than resident females. Probability of nest survival $(\overline{\mathrm{x}} \pm \mathrm{SE})$ was good for both translocated $(0.72 \pm 0.17)$ and resident females $(0.50 \pm 0.16)$, and renests were rare. Probability of brood survival was higher among translocated $(0.85 \pm 0.14)$ than resident females $(0.25 \pm 0.12)$, partly as a result of inclement weather in 2006. Fecundity, estimated as female fledglings per breeding female, was relatively low for both translocated $(0.9 \pm 0.3)$ and resident females $(0.3 \pm 0.2)$. No mortalities occurred among radio-marked female ptarmigan during the 10 -week breeding season, and the probability of annual survival for females in 2005-2006 was between 0.38 and 0.75 . Translocations were successful because females survived, successfully nested, and recruited offspring during the establishment stage. Post-release monitoring provided useful demographic data in this study and should be a key component of translocation programs for wildlife restoration. Future population surveys and additional translocations may be required to ensure long-term viability of the reintroduced population of ptarmigan at Agattu Island. Received 31 July 2008. Accepted 16 July 2009.
\end{abstract}

Reintroductions and other translocations are an important tool for restoring and enhancing plant and animal populations within their native

\footnotetext{
${ }^{1}$ Division of Biology, 116 Ackert Hall, Kansas State University, Manhattan, KS 66506, USA.

${ }^{2}$ U.S. Fish and Wildlife Service, Alaska Maritime National Wildlife Refuge, 95 Sterling Highway, Suite 1, Homer, AK 99603, USA.

${ }^{3}$ Grouse Inc., 5572 North Ventana Vista Road, Tucson, AZ 85750, USA.

${ }^{4}$ Corresponding author; e-mail: bsanderc@ksu.edu
}

geographic range (Griffith et al. 1989, Snyder et al. 1999, Ewen and Armstrong 2007). Greater effort may be allocated to moving animals if resources are limited, rather than to post-release monitoring needed to evaluate project success. However, post-release monitoring is critical because it allows estimation of the demographic parameters needed to evaluate status of reintroduced populations. Population models can then be used to evaluate the effects of removals on source populations, and management strategies and 
environmental factors which may affect the eventual success or failure of newly established populations (Sarrazin and Legendre 2000, Armstrong et al. 2007, Dimond and Armstrong 2007, Reynolds et al. 2008).

Translocations have been widely used with continental populations of upland gamebirds. Release of wild-caught birds has been used to establish new breeding populations of Whitetailed Ptarmigan (Lagopus leucura) (Braun et al. 1978, Hoffman and Giesen 1983, Clarke and Johnson 1990) and Ruffed Grouse (Bonasa umbellus) (Moran and Palmer 1963, Kurzejeski and Root 1988). Reintroductions have been used to bolster declining or isolated populations of prairie grouse (Tympanuchus spp.) (Snyder et al. 1999, Coates et al. 2006) and Greater SageGrouse (Centrocercus urophasianus) (Reese and Connelly 1997, Baxter et al. 2008). Translocations have also been an essential component of applied conservation for populations of birds on oceanic islands, including waterfowl (Reynolds et al. 2008), flightless rails and parrots (Clout and Craig 1995, Jamieson and Wilson 2003), and songbirds (Komdeur 1994, Armstrong et al. 2002, Robertson et al. 2006, Ewen and Armstrong 2007). Restoration of insular populations poses particular challenges because life-history traits of island and mainland vertebrates can be highly divergent with differences in demography, behavior, and morphology (Stamps and Buechner 1985, Blondel 2000). For example, island populations of waterfowl, grouse, and songbirds tend to breed later, lay smaller clutches of larger eggs, and have higher adult survival than mainland populations (Mercer 1967, Blondel 1985, Rohwer 1988, Atwood et al. 1990, Blondel et al. 1992, Wiggins et al. 1998).

The Aleutian Archipelago of western Alaska consists of $>450$ isolated islands with large populations of breeding seabirds. Historically, the Aleutian Islands had no native terrestrial mammals west of Umnak Island (Murie 1959). Island populations of birds were negatively impacted by deliberate introductions of arctic fox (Alopex lagopus) by fur trappers between 1750 and 1940 (Maron et al. 2006). Depredation of eggs, young, and breeding birds led to steep population declines and local extirpation of waterfowl, seabirds, and terrestrial birds on islands where foxes were present (Bailey 1993). The U.S. Fish and Wildlife Service (USFWS) began systematic removal of foxes in 1949, as part of recovery efforts for Aleutian Cackling Geese (Branta hutchinsii leucopareia), as well as seabirds of conservation concern (Springer et al. 1977, Byrd et al. 1997, Williams et al. 2003).

Rock Ptarmigan (Lagopus muta) are arcticbreeding grouse with a Holarctic distribution (Holder and Montgomerie 1993); eight subspecies have been described from the Aleutian Islands based on allopatric distributions and phenotypic differences in plumage coloration (Holder et al. 2000, 2004). Evermann's Rock Ptarmigan (L. m. evermanni) is an endemic subspecies confined to the Near Islands group in the western Aleutian Archipelago. It is the only subspecies where males have a black nuptial plumage (Frontispiece), and has unique population genetics that distinguish it from all other subspecies of Rock Ptarmigan in the Aleutians and elsewhere (Holder et al. 2000). Evermann's Rock Ptarmigan were historically present on all islands in the Near Islands group but introduced foxes reduced their range to Attu Island and an estimated population size of $\sim 1,000$ birds (Ebbert and Byrd 2002). Arctic fox are still present on the islands of Nizki-Alaid and Shemya but were eradicated from Agattu Island and Attu Island by 1979 and 1999, respectively (Bailey 1993, Ebbert and Byrd 2002). Evermann's Rock Ptarmigan, due to their limited geographic range and small population size, have been designated birds of special management concern by the USFWS.

We report results from a field study of a newly established island population of Evermann's Rock Ptarmigan. Prior to our project, comprehensive surveys by the Alaska Maritime National Wildlife Refuge indicated that ptarmigan and foxes were absent on Agattu Island. Ptarmigan may disperse across marine waters (Zimmerman et al. 2005), but natural recolonization across the $28 \mathrm{~km}$ strait between the islands of Attu and Agattu had not occurred in the 25-year period since foxes were eradicated. Thus, we translocated wild-caught ptarmigan over a 4-year period and conducted intensive post-release monitoring at Agattu Island in the last 2 years of the project. Ecological studies of Rock Ptarmigan in the Aleutians have been limited to studies of molt and diet of L. m. gabrielsoni at Amchitka Island (Jacobsen et al. 1983, Emison and White 1988), and our project is the first demographic study of an island population of ptarmigan in Alaska. Our main goal was to compare the demographic rates of translocated and resident ptarmigan, and to evaluate the 
efficacy of translocations for restoration of insular populations of landbirds. A secondary goal was to compare life history traits between insular and mainland populations of Rock Ptarmigan that might influence translocation success for subspecies endemic to the Aleutian Islands.

\section{METHODS}

Study Area.-Attu $\left(52.85^{\circ} \mathrm{N}, 173.19^{\circ} \mathrm{E}\right.$; 89,279 ha) and Agattu $\left(52.43^{\circ} \mathrm{N}, 173.60^{\circ} \mathrm{E}\right.$; $22,474 \mathrm{ha}$ ) are in the Near Islands group in the western range of the Aleutian archipelago and part of the Alaska Maritime National Wildlife Refuge. Attu is a mountainous island with steep hillsides rising from sea level to elevations $>600 \mathrm{~m}$ (highest point: $861 \mathrm{~m}$ ). Most of the land mass of Agattu Island is $<230 \mathrm{~m}$ in elevation but a mountain range composed of seven major submassifs lies along the north side and extends from Armeria Bay eastward to Krugloi Point (highest point: $693 \mathrm{~m}$ ). The dominant plant community in the Near Islands is maritime tundra because the climate is consistently cool, wet, and windy (Maron et al. 2006). Mean minimum and maximum temperatures are 6.5 and $9.2^{\circ} \mathrm{C}$, total precipitation is $6.8 \mathrm{~cm}$ per month, and wind velocities average $42 \mathrm{kph}$ in the 3-month period from June to August (climate data from Shemya Island, $30 \mathrm{~km}$ northeast of Agattu Island). Glaucous-winged Gulls (Larus glaucescens) and Common Ravens (Corvus corax) were potential predators of eggs and chicks, whereas Peregrine Falcons (Falco peregrinus) and Snowy Owls (Nyctea scandiaca) were a threat to adult ptarmigan (Gibson and Byrd 2007). Agattu Island does not have introduced species of rats (Rattus spp.), which are a problem elsewhere in the Aleutian Islands (Major et al. 2006).

Translocations.-Five translocations from Attu Island were conducted to reintroduce Evermann's Rock Ptarmigan to Agattu Island: four during May to June, 2003-2006 and one during September 2003. Translocations could not be conducted at other times of year in this remote area because logistical support was not available and environmental conditions were hazardous. Ptarmigan were live-captured at Attu Island using noose poles, noose carpets, and ground nets. Birds were held for up to $48 \mathrm{hrs}$ in fiberglass transport containers and provided small pieces of melon as a source of food and water. The $28-\mathrm{km}$ strait between the islands of Attu and Agattu required $3 \mathrm{hrs}$ to traverse on the research vessel $\mathrm{M} / \mathrm{V}$
Tiglax. Ptarmigan were immediately released upon arrival at Agattu Island at one of three sites: McDonald Cove on the east coast (2003), Karab Cove on the south coast (2004-2005), or Binnacle Bay on the north coast (2006). Loss of body mass of translocated ptarmigan was measured by subtracting mass at release from mass at capture. We adjusted the difference in body mass by egg mass $(21 \mathrm{~g}$ per egg, Holder and Montgomerie 1993 ) in cases where females laid eggs during the holding period. Necropsies of birds that died during handling or after release were conducted shortly after recovery of the carcass by a wildlife veterinarian (W. P. Taylor, Alaska Fish and Game Department).

Field Methods.-We conducted post-release monitoring at Agattu Island from late May to mid-August in 2005 and 2006 to estimate the fecundity and survival of female Evermann's Rock Ptarmigan (Kaler 2007). Our study sample included newly translocated birds and resident ptarmigan encountered at Agattu Island. The resident population included marked birds surviving from previous translocations and their unmarked offspring. All ptarmigan released were individually banded and color banded with batch marks (2003-2004) or individual band combinations (2005-2006) at first capture. Yearlings and adults were distinguished by patterns of pigmentation and shape of the wing primaries (Weeden and Watson 1967). Females were fitted with radio transmitters attached with either a bib (2005: $15 \mathrm{~g}$, Telemetry Solutions, Concord, CA, USA) or a necklace harness (2006: 6 g, Holohil Ltd., Carp, ON, Canada). Radio transmitters had a battery life of 12-18 months and were equipped with mortality switches to facilitate detection of dropped transmitters and mortality events. Radio-marked birds were tracked with a portable radio receiver (R2000, Advanced Telemetry Systems, Isanti, MN, USA) and 3-element Yagi antenna. We started radio-tracking immediately after release and relocated females daily by radio triangulation until nests were located. All points were recorded in Universal Transverse Mercator (UTM) coordinates using a hand-held Global Positioning System receiver (Garmin GPSmap 76; Garmin International, Olathe, KS, USA).

Nests of translocated ptarmigan were located by radiotelemetry whereas nests of resident ptarmigan were located by searching suitable nest habitat around roosts of males, which often acted as sentinels (Holder and Montgomerie 1993). 
Unmarked females were captured with noose poles on territories or with dip nets at nest sites, and were marked with radio transmitters. We did not examine the eggs if a nest was discovered during egg-laying and returned after the clutch had been completed. We counted the eggs, if a nest was discovered during incubation, measured $( \pm 0.1 \mathrm{~mm}$ ) length (L) and width (W) of all eggs, and floated the eggs in a small cup of lukewarm water to estimate stage of incubation (Westerskov 1950). Buoyancy of eggs was related to stage of incubation as: flat on the bottom of the container $=0$ days, $45^{\circ}=5$ days, $90^{\circ}=10$ days, floating at surface $=13$ days, and a $\sim 18 \mathrm{~mm}$ diameter circle protruding above the water surface $=18$ days. The onset of hatching was detected by days 19 , 20 , and 21 of incubation by tapping, raised starshaped pips in the egg shell, and hole-pipped eggs, respectively.

Female nest attendance was checked every 3-4 days during incubation by triangulating the radio signal at distances $>30 \mathrm{~m}$ from the nest site. Nests were visited every 1-2 days around the predicted hatching date to capture young and ascertain nest fate. We considered nests to be abandoned if a female ceased nest attendance during egg-laying or incubation, depredated if the eggs were destroyed or removed before the expected hatch date, and successful if egg shells with detached membranes were left in the nest bowl after the chicks had departed or if we captured at least one chick at or near the nest. We counted offspring in broods $<15$ days of age with binoculars from $>50 \mathrm{~m}$ and flushed broods 2-3 times at 15-25 days of age to calculate survival of young after hatching.

Demographic Parameters.-Demographic performance of ptarmigan is, at times, affected by female age or annual conditions (Watson 1965, Steen and Unander 1985, Gardarsson 1988, Novoa et al. 2008). Our sample sizes were small and we pooled data across age classes and years to compare the demography of translocated and resident Rock Ptarmigan. We calculated 10 demographic parameters for breeding females (after Sandercock et al. 2005).

(1) Date of clutch initiation was calculated by backdating from stage of egg-laying, stage of incubation, or the date of hatching. We assumed that Rock Ptarmigan laid one egg/ day, started incubation on the penultimate egg, and had an average incubation period of 21 days (Holder and Montgomerie 1993).
(2) Total clutch laid (TCL) was the total number of eggs laid in the clutch, recorded during the first visit to the nest during incubation.

(3) Egg volume $(V)$ was estimated from linear measurements of ptarmigan eggs using $V=$ $k \mathrm{LW}^{2}$, where $k=0.49$ for Willow Ptarmigan (L. lagopus), $\mathrm{L}=$ egg length, and $\mathrm{W}=$ egg width (Sandercock and Pedersen 1994). We calculated average egg volume per clutch because eggs within a nest were not independent observations.

(4) Nest survival until hatching (NEST) was the probability that at least one egg hatched and produced a chick that departed the nest. Values of NEST $<1$ included total clutch losses due to abandonment and predation.

(5) Renesting (RENEST) was the probability that a female laid a replacement clutch, conditional upon loss of her first clutch.

(6) Chicks/egg laid (C/E) was the percentage of eggs laid that eventually hatched and produced chicks that left the nest. $\mathrm{C} / \mathrm{E}$ was calculated only for nests that survived incubation and hatched at least one egg. Values of $\mathrm{C} / \mathrm{E}<1$ included partial clutch losses due to eggs that disappeared during incubation and eggs that survived incubation but failed to hatch.

(7) Brood survival until fledging (FLED) was the probability that at least one chick survived from hatching until fledging at 15-25 days of age. Fledglings completed growth of juvenal feathers by 2 weeks and began to evade observers with short flights instead of running and hiding. Values of FLED $<1$ were due to total brood failure, which was readily ascertained by the behavior and movements of females. If females lost their brood, they flushed during approach by an observer or joined small groups of failed breeders.

(8) Fledglings/chick hatched (F/C) was the percentage of hatched chicks that left the nest and survived until fledging at 15-25 days. F/C was calculated only for broods that survived the brood-rearing period and fledged at least one chick.

(9) Seasonal survival of females was calculated by monitoring radio-marked females over the 10 -week breeding season. We left-censored a 2-week acclimation period to control for potential effects of higher mortality rates immediately following stress of capture, 
transport, release in a new environment, and attachment of the radio transmitter.

(10) Annual survival of females was calculated from the return rates of radio-marked birds from 2005 to 2006 . We conducted intensive searches of territories for all radio-marked females in 2006. Birds relocated alive in 2006 were known survivors whereas radio transmitters recovered near scattered feathers or carcass remains were considered known mortalities. Female fate was unknown if birds were not relocated or if radio transmitters were recovered without accompanying remains.

Estimation of Fecundity.-We calculated a synthetic estimate of fecundity $(F)$ as the expected number of female fledglings produced per breeding female per year. We controlled for possible nest losses before discovery by an observer, and differences in renesting rates, by first calculating the number of eggs surviving until hatching for each breeding female $(E)$ :

$$
\begin{aligned}
E= & \left(\mathrm{TCL}_{1} \times \mathrm{NEST}\right)+ \\
& \left([1-\mathrm{NEST}] \times \mathrm{RENEST} \times \mathrm{TCL}_{2} \times \mathrm{NEST}\right)
\end{aligned}
$$

where $\mathrm{TCL}_{n}=$ total clutch laid, subscripts 1 and 2 are values for first nests and renests, NEST = probability of nest survival, and RENEST = probability of renesting after clutch loss. We calculated fecundity $(F)$ as:

$$
F=E \times \mathrm{C} / \mathrm{E} \times \mathrm{FLED} \times \mathrm{F} / \mathrm{C} \times 0.5
$$

where $E=$ the number of surviving eggs, $\mathrm{C} / \mathrm{E}=$ percentage of chicks hatched/egg laid, FLED = probability of brood survival until fledging, $\mathrm{F} / \mathrm{C}=$ percentage of fledglings produced/chick leaving the nest, and 0.5 is the proportion of females based on a $1: 1$ sex ratio.

Statistical Analysis.-Comparisons of demographic parameters between translocated and resident females were conducted using statistical procedures in Program SAS (Version 8.1, SAS Institute Inc., Cary, NC, USA). Sample sizes differed among some components of fecundity because we lacked complete information for a few nests and losses to predators caused attrition over the breeding season. Continuous data were compared with two sample $t$-tests and frequency data were compared with contingency tests. Post hoc comparisons of survival rates were conducted with Program CONTRAST (USGS, Patuxent Wildlife Research Center, Laurel, MD, USA). All tests were two-tailed and considered significant at $\alpha<0.05$. Means \pm SE are presented.

We estimated daily survival rates of nests and broods during the incubation and brood-rearing periods with the nest survival procedure of Program MARK (Version 4.1, G. C. White, Colorado State University, Fort Collins, CO, USA). We collected data for nests for a 63-day exposure period from 1 June until 2 August, and for broods for a 38-day exposure period from 28 June until 5 August. We created encounter histories for each nest and brood survival analyses with five types of information (Dinsmore et al. 2002): (1) the day the nest or brood was found $(k),(2)$ the last day it was known to be active $(l),(3)$ the last day it was checked $(m),(4)$ the fate $(f)$ where $0=$ successful and $1=$ depredated, and (5) the number of nests or broods with the same encounter history $(n)$. All assumptions of the nest survival model were met in this study (Kaler 2007).

We considered five candidate models in our analyses of nest and brood survival. We expected that translocated females might have lower nest survival rates than resident females, and daily survival rates might vary during the breeding season. Survival rates of ground nests of precocial birds might be expected to vary seasonally if vegetative cover changes, poorly concealed nests are selectively destroyed, or predator activity is affected by nest densities and availability of alternative prey (Klett and Johnson 1982, Dinsmore et al. 2002, Wilson et al. 2007). Similarly, brood survival rates might be lowest after nest departure and improve as chicks begin to thermoregulate and fly. Thus, our global model included the effects of female group (translocated vs. resident), a linear effect of time, and the interaction of these factors $\left(S_{\text {group }} \times\right.$ linear $)$. We also fit reduced models with main effects $\left(S_{\text {group }}+\right.$ linear $)$, single factors $\left(S_{\text {group }}, S_{\text {time }}\right)$, and a model that constrained daily survival to be a constant $\left(S_{\text {constant }}\right)$. Global models are saturated in the nest survival model, and adjustments for overdispersion are not possible because the variance inflation factor $(c)$ is not identifiable (Dinsmore et al. 2002). All models were fit to the data using design matrices and the logit-link function in Program MARK.

Model selection was based on an information theoretic approach (Burnham and Anderson 1998). The model with the lowest Akaike's 
Information Criterion corrected for small sample sizes $\left(\mathrm{AIC}_{c}\right)$ value was the best fit and models with $\Delta \mathrm{AIC}_{c} \leq 2$ were equally parsimonious. We based inference on differences in deviance in cases where the difference in number of parameters was one $(\Delta K=1)$. We used ratios of Akaike weights to quantify the extent of support among models $\left(w_{i} / w_{j}\right)$.

We calculated parameter estimates with unconditional variances with the model-averaging procedure of Program MARK to examine seasonal variation in daily survival rates. We extrapolated daily survival rates using $\hat{S}^{d u r}$, where $\hat{S}=$ the daily survival rate of nests or broods, and $d u r$ $=$ the duration of the nesting or brood-rearing stages to obtain stage-specific estimates of the probabilities of nest and brood survival. For example, the duration of an eight-egg nesting attempt was 28 days, calculated as the duration of the egg-laying ( 8 days) and incubation periods (21 days) with incubation starting after laying of the penultimate egg ( -1 day). The duration of the brood-rearing period was 20 days. Variances of stage-specific estimates were calculated using the delta method, following formulae and methods described by Powell (2007).

We used parametric bootstrapping to obtain confidence intervals for our synthetic estimates of fecundity $(F)$ (Gotelli and Ellison 2004). We generated bootstrap distributions using tools of Program MATLAB (Version 6.5, MathWorks, Natick, MA, USA). Estimates of means and variances were taken directly from our parameter estimates with the exception of the probability of renesting where the variance was estimated as $\operatorname{Var}(p)=p(1-p) / n$, where $p$ is the probability and $n$ is the total sample size. Total clutch laid was modeled as draws from a normal distribution whereas probabilities were modeled as draws from beta distributions to bound draws within the range of 0 and 1 . We drew a set of seven demographic rates at random for each bootstrap replicate, combined the estimates to calculate fecundity, and repeated these steps for 1,000 bootstrap iterations. Bootstrapping of fecundity was conducted separately for translocated, resident, and pooled females. We generated a distribution of differences between random pairs of bootstrap values for translocated and resident females to compare groups, and calculated a $P$-value by recording the number of bootstrap differences that were greater than the observed difference between means (Gotelli and Ellison 2004).
TABLE 1. Number of Evermann's Rock Ptarmigan translocated from Attu Island to Agattu Island, Aleutian Archipelago, Alaska, in May to June 2003-2006 and September 2003.

\begin{tabular}{lrccc}
\hline Year & Males & Females & Juveniles & Totals \\
\hline 2003 & 11 & 13 & 2 & 26 \\
2004 & 11 & 16 & 0 & 27 \\
2005 & 4 & 10 & 0 & 14 \\
2006 & 5 & 3 & 0 & 8 \\
Totals & 31 & 42 & 2 & 75 \\
\hline
\end{tabular}

\section{RESULTS}

We translocated 75 Evermann's Rock Ptarmigan from Attu Island to Agattu Island over a 4year period (2003-2006, Table 1). We monitored reproduction and survival rates of 29 radiomarked female ptarmigan (translocated: $n=13$; resident: $n=16$ ) from late May to mid-August during a 2-year radiotelemetry study (20052006). The proportion of females that were adults was higher among translocated $(92 \%, n=13)$ than resident birds $(56 \%, n=16$, Fisher's Exact test, $P=0.044)$, but age-classes were pooled for analyses because sample sizes were small. Our study sample included 28 nests (translocated: $n=$ 10; resident: $n=18$, including 2 renests) and 21 broods (translocated: $n=8$; resident: $n=13$ ).

Translocations.-Female ptarmigan translocated from Attu to Agattu Island in 2005-2006 $(n=13)$ were in breeding condition: $30.8 \%$ had partial brood patches and $46.2 \%$ laid an egg in the holding containers during transport. Female mass at capture averaged $568 \pm 16 \mathrm{~g}(n=31)$ and translocated females lost an average of $9 \%$ of their total body mass ( $\overline{\mathrm{x}} \pm$ SE loss: $-57 \pm 15 \mathrm{~g}, n=12$ ). Only one mortality occurred during the holding and transport periods in the 4-year period. A juvenile male died during holding but we were unable to assign cause of death at necropsy. Two mortalities occurred at Agattu Island during post-release monitoring in the last 2 years of the study. In both cases, radiomarked females died within 2 weeks of release. One female was recovered 2 days after release $390 \mathrm{~m}$ from the release site and necropsy indicated that she drowned in a small tundra pool. A second female was recovered 10 days after release $914 \mathrm{~m}$ from the release site; evidence at the recovery site indicated she was killed by a raptor. Release site had little effect on translocation success because surviving birds quickly dispersed to settle in alpine habitats at the northern part of Agattu Island. 
TABLE 2. Demographic parameters of translocated and resident Evermann's Rock Ptarmigan at Agattu Island, Aleutian Archipelago, Alaska, 2005-2006. The first three parameters were calculated for first nests only. Data are presented as means $\pm \operatorname{SE}(n)$.

\begin{tabular}{|c|c|c|c|c|c|}
\hline Parameter & Translocated & Resident & Pooled & Statistic & $P \leq$ \\
\hline Date of clutch initiation (days) & 16 June $\pm 1.0(10)$ & 8 June $\pm 1.3(16)$ & 11 June $\pm 1.2(26)$ & $t_{24}=-4.5$ & 0.001 \\
\hline Total clutch laid (eggs) & $6.8 \pm 0.3(10)$ & $8.3 \pm 0.2(15)$ & $7.7 \pm 0.2(25)$ & $t_{25}=4.2$ & 0.001 \\
\hline Mean egg volume $\left(\mathrm{cm}^{3}\right)$ & $23.1 \pm 0.6(8)$ & $23.3 \pm 0.2(16)$ & $23.2 \pm 0.2(24)$ & $t_{22}=0.41$ & 0.68 \\
\hline Probability of nest survival & $0.724 \pm 0.166(10)$ & $0.500 \pm 0.155(18)$ & $0.588 \pm 0.118(28)$ & $\chi_{1}^{2}=1.8$ & 0.18 \\
\hline Probability of renesting & $0(2)$ & $0.50(4)$ & $0.33(6)$ & Fisher's Exact & 0.47 \\
\hline Chicks/egg laid (\%) & $85.7 \pm 4.6(8)$ & $82.3 \pm 5.1(13)$ & $83.6 \pm 3.5(21)$ & $t_{19}=-0.5$ & 0.66 \\
\hline Probability of brood survival & $0.849 \pm 0.139(8)$ & $0.251 \pm 0.123(13)$ & ) $0.470 \pm 0.119(21)$ & $\chi_{1}^{2}=10.4$ & 0.002 \\
\hline Fledglings/chick hatched $(\%)$ & $48.5 \pm 1.1(7)$ & $53.9 \pm 3.8(4)$ & $50.4 \pm 0.7(11)$ & $t_{9}=0.4$ & 0.73 \\
\hline $\begin{array}{l}\text { Fecundity (female fledglings/ } \\
\text { breeding female/year) }\end{array}$ & $0.9 \pm 0.3$ & $0.3 \pm 0.2$ & $0.5 \pm 0.2$ & Bootstrap & 0.48 \\
\hline
\end{tabular}

Timing of Clutch Initiation, Total Clutch Laid, and Egg Volume.-All translocated females that survived the 2-week acclimation period initiated clutches on Agattu Island. The interval between release and onset of egg-laying was $13.1 \pm 0.9$ days for translocated females $(n=10)$. The average date of clutch initiation was 16 June for translocated females, which was 8 days later than an average date of 8 June for resident hens (Table 2). Total clutch laid in first nests by translocated females (6.8 eggs) was 1.5 eggs smaller than the average clutch size of resident hens (8.3 eggs). Mean egg volume did not differ between resident and translocated females, and averaged $23.2 \mathrm{~cm}^{3}$ overall.
Nest Survival, Renesting, and Chicks/Egg.-We used encounter histories from 28 nests (10 translocated and 18 resident, 2 females included in both years) to estimate daily survival rates for nests. Nests were monitored over a 63-day exposure period (day $1=1$ June). The minimum $\mathrm{AIC}_{c}$ model contained a linear effect of time over the breeding season $\left(S_{\text {linear }}\right.$, Table 3$)$. The minimum $\mathrm{AIC}_{c}$ model had 1.3-2.4 times greater support than the other candidate models but all five models were equally parsimonious $\left(\Delta \mathrm{AIC}_{c}<1.8\right)$.

The slope coefficient for the linear effect indicated that nest survival declined over the breeding season (from model $S_{\text {linear: }}: \hat{\beta}=-0.07 \pm$ 0.04 , logit scale), particularly in the latter part of

TABLE 3. Model selection results for daily survival rates $(S)$ of nests and broods of Evermann's Rock Ptarmigan at Agattu Island, Aleutian Archipelago, Alaska, 2005-2006. Model fit was described by the number of parameters $(K)$, model deviance (Dev), Akaike's Information Criterion corrected for small sample size ( $\mathrm{AIC}_{c}$ ), deviations from the minimum-AIC model $\left(\Delta \mathrm{AIC}_{c}\right)$, and Akaike weights $\left(w_{i}\right)$. Models for daily survival $(S)$ included comparisons of resident vs. translocated birds (group), a seasonal effect of time (linear), factorial $(X)$ and main effects models $(+)$, and a reduced model with no effects (constant). Exposure periods were 63 days for nesting (day $1=1$ June) and 38 days for brood-rearing (day $1=$ 28 June).

\begin{tabular}{llllll}
\hline \multicolumn{1}{c}{ Model } & $K$ & $\mathrm{Dev}$ & $\mathrm{AIC}_{c}$ & $\Delta \mathrm{AIC}_{c}$ & $w_{i}$ \\
\hline Nests & & & & & \\
$\quad S_{\text {linear }}$ & 2 & 51.5 & 55.5 & 0.00 & 0.300 \\
$S_{\text {constant }}$ & 1 & 54.0 & 56.0 & 0.54 & 0.229 \\
$S_{\text {group }+ \text { linear }}$ & 3 & 50.2 & 56.3 & 0.76 & 0.205 \\
$S_{\text {group }} \times$ linear & 4 & 48.9 & 57.0 & 1.52 & 0.140 \\
$S_{\text {group }}$ & 2 & 53.2 & 57.2 & 1.74 & 0.126 \\
Broods & & & & \\
$S_{\text {group }}$ & 2 & 43.2 & 47.2 & 0.00 & 0.443 \\
$S_{\text {group } \times \text { linear }}$ & 4 & 39.7 & 47.9 & 0.68 & 0.316 \\
$S_{\text {group }+ \text { linear }}$ & 3 & 43.1 & 49.3 & 2.02 & 0.162 \\
$S_{\text {constant }}$ & 1 & 49.7 & 51.8 & 4.52 & 0.046 \\
$S_{\text {linear }}$ & 2 & 48.4 & 52.4 & 5.20 & 0.033 \\
\hline
\end{tabular}




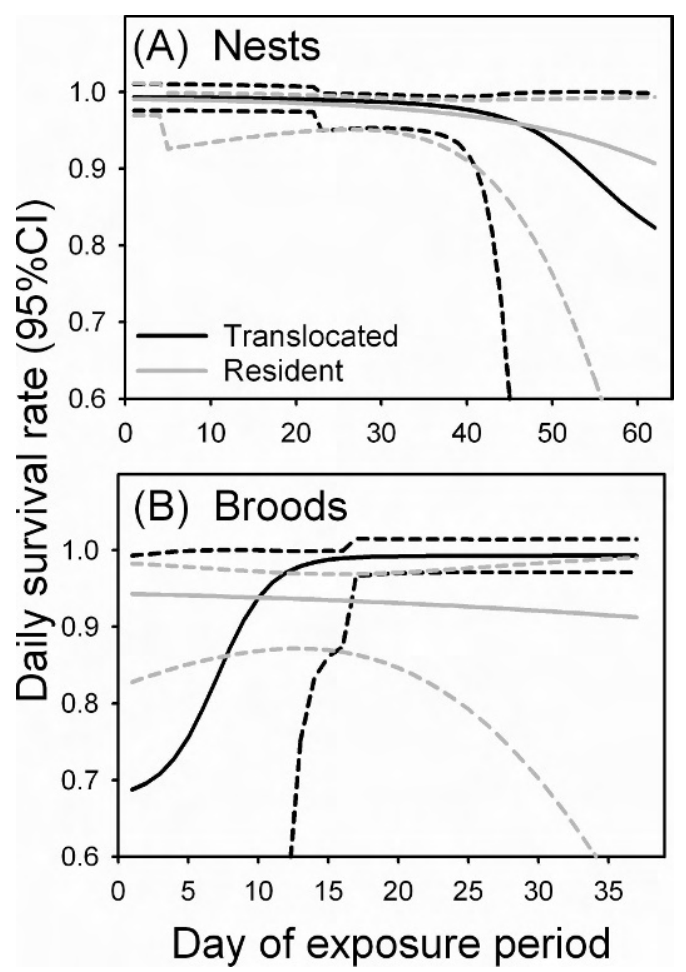

FIG. 1. Daily survival rates for nests and broods of translocated and resident female Rock Ptarmigan at Agattu Island, Alaska, 2005-2006 ( $n=27$ nests and 21 broods). Estimates were calculated by model-averaging in Program MARK. Exposure periods were 63 days for nesting (day 1 $=1$ June) and 38 days for brood-rearing (day $1=28$ June).

the season (Fig. 1A). Estimates of daily survival rates (from model $S_{\text {group}}$ ) revealed that nest survival was similar for translocated $(\hat{S}=0.988$ $\pm 0.008)$ and resident females $(\hat{S}=0.976 \pm$ 0.011 ), and was high overall (from model $S_{\text {constant: }}$ : $\hat{S}=0.981 \pm 0.007)$. Extrapolation of daily survival rates over the duration of a nesting attempt (27 to 28 days for 7 - to 8 -egg clutches) yielded estimates of the probability of nest survival that were $0.724 \pm 0.166$ for translocated females, $0.500 \pm 0.155$ for resident females, and $0.588 \pm 0.118$ for all females combined.

Six first nesting attempts failed because of nest predation or abandonment. Two resident females that renested lost their first nests 2 days before onset of incubation and at 12 days of incubation, and initiated renests after intervals of 13 and 11 days, respectively. Clutch size of the two renests was 5 and 6 eggs. Translocated and resident females that did not renest lost their nests at more advanced stages of incubation (12-23 days, $n=$
4). The percentage of viable eggs that hatched and produced 1-day old chicks did not differ between resident and translocated females, if the nest survived incubation, and was $83.6 \%$ overall.

Brood Survival and Fledglings per Chick.-We used encounter histories from 21 radio-marked females that successfully hatched young ( 8 translocated and 13 resident, 1 female included in both years) to estimate daily survival rates for broods. Broods were monitored over a 34-day exposure period (day $1=28$ June). The minimum $\mathrm{AIC}_{c}$ model included an effect of group with a difference between translocated and resident birds ( $S_{\text {group }}$, Table 3$)$. Two additional models with interactive and additive effects between group and a linear effect of time $\left(S_{\text {group }} \times\right.$ linear,$\left.S_{\text {group }+ \text { linear }}\right)$ were equally parsimonious or nearly so $\left(\Delta \mathrm{AIC}_{c}<\right.$ 2.02), but the minimum $\mathrm{AIC}_{c}$ model had 1.4-2.7 times greater support.

The slope coefficient for the effect of group (from model $S_{\text {group }} \times$ linear: $\hat{\beta}=6.87 \pm 6.71$, logit scale) was larger than the linear effect of time $(\hat{\beta}$ $=0.53 \pm 0.51)$ or the interaction of the two factors $(\hat{\beta}=-0.57 \pm 0.51)$. Brood survival of translocated females was initially low and increased over the exposure period, whereas resident birds had moderate brood survival (Fig. 1B). Overall estimates of daily survival rates (from model $S_{\text {group }}$ ) indicated brood survival was higher among translocated females $(\hat{S}=$ $0.992 \pm 0.008)$ than resident hens $(\hat{S}=0.933 \pm$ 0.022 ). Daily survival rates of broods for all females combined (from model $S_{\text {constant }}: \hat{S}=$ $0.963 \pm 0.012)$ were not different from the daily survival rates of nests $\left(\hat{S}=0.981 \pm 0.007, \chi_{1}^{2}=\right.$ $1.71, P=0.19)$. Extrapolation of daily survival rates over the duration of brood-rearing ( 20 days) yielded estimates of the probability of brood survival that were $0.849 \pm 0.139$ for translocated females, $0.251 \pm 0.123$ for resident females, and $0.470 \pm 0.119$ for all females. The percentage of chicks that successfully fledged if the brood survived the brood-rearing stage did not differ between resident and translocated females, and was $50.4 \%$ overall.

Fecundity.-We combined our estimates of demographic parameters to calculate a synthetic estimate of fecundity that controlled for nest exposure before nest discovery and productivity from renests. Fecundity tended to be higher among translocated birds $(F=0.9 \pm 0.3$ female fledglings/female) than residents $(F=0.3 \pm 0.2)$, but the difference was not significant (Table 2). 
Survival of Females.-We monitored seasonal survival during the nesting and brood-rearing period for 26 female ptarmigan (10 translocated and 16 resident). All females survived the 10week breeding season and no mortalities were observed during either 2005 or 2006 . We searched during the 2006 breeding season for 16 females that had been radiomarked in 2005 to assess overwinter female survival. Of the 16 females, $37.5 \%$ were detected alive, $31.3 \%$ were dead recoveries, and $31.3 \%$ were not relocated. The frequency of known mortalities was equivalent in translocated $(30 \%, n=10)$ and resident females (33\%, $n=6$, Fisher's Exact test, $P=1.0$ ). Surviving females had strong site fidelity and distance between nest locations in consecutive years averaged $123 \pm 34 \mathrm{~m}(n=5)$. We intensively searched female territories and our minimum estimate of annual survival would be 0.38 if all missing females had died. However, if missing females survived to disperse elsewhere on the island, annual survival of females could be as high as 0.75 .

\section{DISCUSSION}

Our field study is one of the first investigations of the effects of translocation on an insular population of an upland gamebird, and we provide the first estimates of demographic parameters for any of the subspecies of Rock Ptarmigan that are endemic to the Aleutian Archipelago. Our major conclusions were: (1) translocations had negative impacts on female performance with short-term increases in female mortality, delays in the timing of clutch initiation, and reductions in clutch size; (2) settlement was rapid and unaffected by location of the release sites; (3) translocated and resident females had similar rates of fecundity and survival during the period of population establishment; and (4) island and mainland populations appear to have similar demography, which may have contributed to the success of our reintroductions.

Effects of Translocation on Fecundity.-The negative impacts of translocation from Attu Island to Agattu Island were transitory and had little net effect on productivity. Logistics constrained us to hold birds for up to $48 \mathrm{hrs}$, but mortality rates were low during holding (1.4\%) and comparable to translocations of other grouse $(0 \%$, Hoffman and Giesen 1983; 2.1\%, Baxter et al. 2008) and waterfowl (0\%, Reynolds et al. 2008). Rock Ptarmigan lost an average of $9 \%$ of body mass during transport, and similar rates of loss have been reported for translocated Ruffed Grouse (10\%, Kurzejeski and Root 1988) and Laysan Ducks (Anas laysanensis) (6\%, Reynolds et al. 2008). The only mortalities among radio-marked Rock Ptarmigan were two females that died shortly after release. Mortality rates of wildlife are often higher immediately after translocation, because of the physiological stress of captivity or elevated predation risk due to lack of familiarity with a new environment or attachment of a radio transmitter (Musil et al. 1993, Clout and Craig 1995, Armstrong et al. 1999, Baxter et al. 2008).

Ptarmigan settled quickly into alpine habitats during the establishment stage and all surviving females initiated clutches shortly after release. Future translocations of ptarmigan in the Aleutian Islands can select release sites based on safety of coastal landings without concerns about proximity to suitable habitats. In other species, translocated birds often range widely after release in search of suitable habitat or conspecifics (Musil et al. 1993, Armstrong et al. 1999, Coates et al. 2006), and long distance movements can contribute to higher mortality rates during the acclimation period (Kurzejeski and Root 1988). Our releases may have had greater success because post-release movements were constrained by the limited area of alpine habitat on Agattu Island and habitat quality was restored to historical conditions by eradication of introduced predators. Translocations of birds in breeding condition during the nesting season facilitated rapid settlement and early reproduction, similar to previous releases of ptarmigan (Braun et al. 1978). Translocations of juveniles during the nonbreeding season might have less impact on a source population but could delay establishment because juveniles must survive to the next breeding season and, at times, have lower success as first time breeders (Kurzejeski and Root 1988, Sarrazin and Legendre 2000, Robertson et al. 2006, Baxter et al. 2008, Reynolds et al. 2008).

Translocated females delayed clutch initiation and laid clutches that were 1.5 eggs smaller than nests of resident Evermann's Rock Ptarmigan. Reduced clutch size could have been due to interruptions in egg-laying if translocated females were determinate egg-layers that failed to replace missing eggs laid in clutches at Attu Island or in the handling crates during transit (Sandercock 1993). Alternatively, smaller clutches could have been due to the physiological stress of translocation. White-tailed Ptarmigan breeding in years of 
harsh environmental conditions delay egg-laying and take more incubation breaks to maintain body condition (Wiebe and Martin 2000). Only resident females renested after nest failure in our study. However, females that failed to renest lost their clutches at more advanced stages of incubation when the probability of renesting was presumably low (Robb et al. 1992). Evermann's Rock Ptarmigan laid fewer eggs in renests than first nests, similar to other populations of ptarmigan (Brodsky 1986, Cotter 1999, Sandercock et al. 2005).

Translocated and resident ptarmigan differed primarily in demographic parameters that were recorded at the start of the nesting cycle. The potential demographic impacts of differences in timing of laying and clutch size were largely offset by reproductive losses. Nest and brood survival are expected to improve over the season if vegetative cover increases or predators locate offspring in vulnerable sites earlier in the season (Klett and Johnson 1982, Wilson et al. 2007). Survival of ptarmigan broods at Agattu Island increased during the breeding season, but survival of nests was lowest during the latter part of the exposure period. The lowest rates of daily survival for ptarmigan nests and broods coincided with the hatching period of Aleutian Cackling Geese and increased foraging activity by Glaucous-winged Gulls at inland sites. Gulls primarily hunted for goose eggs and goslings, but incidental predation could have reduced the fecundity of ptarmigan. Predation could potentially be a limiting factor for ptarmigan populations because gull populations are maintained at high levels in the Aleutian Islands by access to refuse from fish processing facilities (Gibson and Byrd 2007).

Ptarmigan young have limited ability to thermoregulate or evade predators in the week after hatching (Scherini et al. 2003, Hannon and Martin 2006). Increases in late season survival of broods could have been due to development of homeothermy and mobility among ptarmigan young or to more favorable climatic conditions during the latter part of the exposure period (Aulie 1976, Steen and Unander 1985). Hatching and fledging success were high, if ptarmigan young survived incubation or brood-rearing, and there was no evidence of deleterious effects caused by inbreeding depression (Briskie and Macintosh 2004).

Synthesis of the major components of reproductive effort showed that fecundity of Evermann's Rock Ptarmigan was relatively low at $<1$ fledgling per breeding female, and that translocated females did not have lower fecundity than resident females in our reintroduced population. If any difference occurred, it was that translocated birds tended to have higher productivity, similar to previous reports for Takahe (Porphyrio hochstetteri) (Jamieson and Wilson 2003). Some variation in productivity could have been explained by female age class and annual variation in demographic rates. Our sample of translocated birds included a high proportion of adults, which at times, have higher reproductive success than yearling Rock Ptarmigan (Steen and Unander 1985, but see Cotter 1999, Scherini et al. 2003). Similarly, annual fecundity of Rock Ptarmigan can be variable and influenced by local environmental factors, including food, predation, and climate (Watson 1965, Gardarsson 1988, Novoa et al. 2008). If conditions are favorable for several consecutive years, ptarmigan numbers should exhibit the exponential growth often reported for populations established by island translocations (Moran and Palmer 1963, Klein 1968, Komdeur 1994, Armstrong et al. 2002).

Survival Rates.-Seasonal survival of female Evermann's Rock Ptarmigan during the breeding period was $100 \%$ as no mortalities were observed. Mortality rates during the breeding season are higher in populations of Rock Ptarmigan where mammalian predators and Gyrfalcons (Falco rusticolus) are a threat (23\%, Gardarsson 1988; 14\%, Cotter et al. 1992; 12\%, Scherini et al. 2003). Annual survival of female Evermann's Rock Ptarmigan was between 0.38 and 0.75 for one interval (2005-2006), and all losses occurred during the fall or winter after we had departed from Agattu Island. Raptors capable of killing adult ptarmigan occurred at relatively low densities during the breeding season (Kaler 2007). Seasonal mortality rates of mainland populations of Willow Ptarmigan are usually highest in autumn during raptor migration (Smith and Willebrand 1999, Hannon et al. 2003). Seasonal mortality rates of Evermann's Rock Ptarmigan may have been higher outside of the breeding season if Snowy Owls and Peregrine Falcons relied on coastal seabirds during summer but spent more time foraging at inland sites during fall and winter (Gibson and Byrd 2007). Our conservative estimate of annual survival of 0.38 for Evermann's Rock Ptarmigan is comparable to estimates of 0.37 to 0.43 for arctic and alpine populations of Willow Ptarmigan (Sandercock et al. 2005). 
TABLE 4. Estimates of five demographic parameters for island (I) and mainland (M) populations of Rock Ptarmigan.

\begin{tabular}{|c|c|c|c|c|c|c|c|c|}
\hline Location & Pop. & Lat. & $\begin{array}{l}\text { Date of clutch } \\
\text { initiation }\end{array}$ & $\begin{array}{l}\text { Clutch } \\
\text { size }\end{array}$ & $\begin{array}{l}\text { Probability of } \\
\text { nest survival }\end{array}$ & $\begin{array}{l}\text { Probability of } \\
\text { brood survival }\end{array}$ & $\begin{array}{l}\text { Probability of } \\
\text { adult survival }\end{array}$ & Source \\
\hline Alaska, USA & I & $53^{\circ} \mathrm{N}$ & 8 June & 8.3 & 0.59 & 0.47 & $0.38-0.75$ & This study \\
\hline Iceland & I & $66^{\circ} \mathrm{N}$ & & $>10.4$ & $>0.90$ & & $0.26-0.82$ & Gardarsson 1988 \\
\hline Norway & I & $78^{\circ} \mathrm{N}$ & & 7.5 & 0.44 & & & Steen and Unander 1985 \\
\hline Italy & M & $46^{\circ} \mathrm{N}$ & 10 June & 6.8 & 0.50 & $0.18-0.67$ & & Scherini et al. 2003 \\
\hline Scotland, UK & M & $57^{\circ} \mathrm{N}$ & Mid June & 6.6 & 0.90 & 0.62 & & Watson 1965 \\
\hline Alaska, USA & M & $65^{\circ} \mathrm{N}$ & & 7.0 & 0.67 & 0.81 & $0.26-0.71$ & Weeden 1965 \\
\hline NWT, Canada & M & $68^{\circ} \mathrm{N}$ & 11 June & 8.8 & & & & Brodsky 1986, 1988 \\
\hline NWT, Canada & M & $69^{\circ} \mathrm{N}$ & 9 June & 8.7 & 0.64 & 0.53 & $0.43-0.82$ & Cotter 1991, 1999 \\
\hline
\end{tabular}

Life-history Traits of Ptarmigan.-Evermann's Rock Ptarmigan are endemic to oceanic islands and are a unique insular form with a black nuptial plumage and distinct population genetics (Holder et al. 2000, 2004). We found little evidence that selection on demography has contributed to development of an insular syndrome in the lifehistory traits of this subspecies, despite distinct differences in morphology. Compared to mainland and island populations of Rock Ptarmigan elsewhere in their Holarctic range, Evermann's Rock Ptarmigan had similar dates of clutch initiation in mid-June, intermediate values for clutch size, and comparable estimates of the probabilities of survival for nests, broods, and adults (Table 4). Evolution of an insular syndrome among the life-traits of vertebrates is frequently attributed to differences in predation and climate regimes between island and mainland sites (Mercer 1967, Stamps and Buechner 1985, Blondel 2000). Isolation reduces the diversity of predator communities and climatic conditions can be less variable due to proximity to coastal waters. These two ecological factors may have had less influence on Evermann's Rock Ptarmigan because the Near Island group supports several species of avian predators and has extreme climatic conditions associated with an exposed location in the northern Pacific Ocean (Maron et al. 2006, Gibson and Byrd 2007). Most of the geographic variation in life-history traits of Rock Ptarmigan and congeneric species appears to be driven by latitudinal and altitudinal gradients in ecological conditions in arctic and alpine environments (Sandercock et al. 2005, Novoa et al. 2008).

\section{CONSERVATION IMPLICATIONS}

Ten features of our project have been identified as factors predicting translocation success for terrestrial vertebrates (Griffith et al. 1989, Snyder et al. 1999, Ewen and Armstrong 2007). Evermann's Rock Ptarmigan are a herbivorous, native gamebird with high reproductive potential that breed as yearlings. We translocated multiple batches of wild-caught birds over a 4-year period, and birds were released into high quality habitat in the core of their historical range which had been restored by eradication of introduced predators. High survival during the breeding season, successful nesting, and recruitment of young birds indicated successful reestablishment of an island population. Small initial populations can risk extinction because of demographic stochasticity, loss of genetic diversity, and inbreeding depression. However, annual surveys in June using playbacks of male vocalizations recorded 26-27 territorial male Evermann's Rock Ptarmigan each year at Agattu Island in 2008-2009, following completion of our field study. An adaptive management strategy based on regular surveys and supplementary translocations will ensure the long-term population viability of Evermann's Rock Ptarmigan at Agattu Island.

\section{ACKNOWLEDGMENTS}

R. B. Benter, J. K. Nooker, M. A. Schroeder, and W. P. Taylor assisted with capture and translocation of ptarmigan from Attu Island to Agattu Island. L. A. Kenney and G. T. Wann were dedicated research assistants for two field seasons at Agattu Island. Captain K. D. Bell and the crew of the M/V Tiglax provided us with safe passage to the outer Aleutians, and G. V. Byrd coordinated logistical support for our field project. The LORAN Station of the U.S. Coast Guard at Attu Island provided housing, meals and other support during our capture effort. D. P. Armstrong and L. N. Ellison offered constructive reviews of the manuscript. Funding for field work for this project was provided by the USFWS, Alaska Maritime National Wildlife Refuge; and the U.S. Missile Defense Agency. The Division of Biology at Kansas State University provided financial support to R. 
S. A. Kaler and B. K. Sandercock. Capture and handling of birds was conducted under protocols approved by the Institutional Animal Care and Use Committee at Kansas State University, and capture and transport permits from the State of Alaska.

\section{LITERATURE CITED}

Armstrong, D. P., I. CAStro, And R. Griffiths. 2007. Using adaptive management to determine requirements of re-introduced populations: the case of the New Zealand Hihi. Journal of Applied Ecology 44:953-962.

Armstrong, D. P., I. Castro, J. C. Alley, B. Feenstra, AND J. K. PERROTT. 1999. Mortality and behaviour of Hihi, an endangered New Zealand honeyeater, in the establishment phase following translocation. Biological Conservation 89:329-339.

Armstrong, D. P., R. S. Davidson, W. J. Dimond, J. K. Perrott, I. Castro, J. G. Ewen, R. Griffiths, and J. TAYLOR. 2002. Population dynamics of reintroduced forest birds on New Zealand islands. Journal of Biogeography 29:609-621.

Atwood, J. L., M. J. Elpers, And C. T. Collins. 1990. Survival of breeders in Santa Cruz Island and mainland California Scrub Jay populations. Condor 92:783-788.

AULIE, A. 1976. The pectoral muscles and the development of thermoregulation in chicks of Willow Ptarmigan (Lagopus lagopus). Comparative Biochemistry and Physiology 53:343-346.

BAILEY, E. 1993. Introduction of foxes to Alaskan Islands: history, effects on avifauna, and eradication. U.S. Fish and Wildlife Service Resource Publication 191. Anchorage, Alaska, USA.

BAXter, R. J., J. T. Flinders, AND D. L. Mitchell. 2008. Survival, movements, and reproduction of translocated Greater Sage-Grouse in Strawberry Valley, Utah. Journal of Wildlife Management 72:179-186.

Blondel, J. 1985. Breeding strategies of the Blue Tit and Coal Tit (Parus) in mainland and island Mediterranean habitats: a comparison. Journal of Animal Ecology 54:531-556.

BLONDEL, J. 2000. Evolution and ecology of birds on islands: trends and prospects. Vie et Milieu-Life and Environment 50:205-220.

Blondel, J., R. Pradel, And J.-D. Lebreton. 1992. Low fecundity insular Blue Tits do not survive better as adults than high fecundity mainland ones. Journal of Animal Ecology 61:205-213.

Braun, C. E., D. H. Nish, and K. M. Giesen. 1978. Release and establishment of White-tailed Ptarmigan in Utah. Southwest Naturalist 23:661-668.

BRISKIE, J. V. AND M. MACKINTOSH. 2004. Hatching failure increases with severity of population bottlenecks in birds. Proceedings of the National Academy of Science of the United States of America 101:558-561.

BRODSKY, L. M. 1986. Correlates and consequences of the mating tactics of male Rock Ptarmigan (Lagopus mutus). Dissertation. Queen's University, Kingston, Ontario, Canada.
BRODSKY, L. M. 1988. Mating tactics of male Rock Ptarmigan Lagopus mutus: a conditional mating strategy. Animal Behaviour 36:335-342.

Burnham, K. P. And D. R. Anderson. 1998. Model selection and inference: a practical informationtheoretic approach. Springer-Verlag, New York, USA.

Byrd, G. V., E. P. Bailey, And W. Stahl. 1997. Restoration of island populations of Black Oystercatchers and Pigeon Guillemots by removing introduced foxes. Colonial Waterbirds 20:253-260.

Clarke, J. A. And R. E. Johnson. 1990. Biogeography of White-tailed Ptarmigan (Lagopus leucurus): implications from an introduced population in the Sierra Nevada. Journal of Biogeography 17:649-656.

Clout, M. N. AND J. L. CRAig. 1995. The conservation of critically endangered flightless birds in New Zealand. Ibis 137 (Supplement): S181-S190.

Coates, P. S., S. J. Stiver, AND D. J. Delehanty. 2006. Using Sharp-tailed Grouse movement patterns to guide release-site selection. Wildlife Society Bulletin 34:1376-1382.

CotTer, R. C. 1991. Population attributes and reproductive biology of Rock Ptarmigan (Lagopus mutus) in the central Canadian arctic. Thesis. University of Alberta, Edmonton, Canada.

CotTer, R. C. 1999. The reproductive biology of Rock Ptarmigan (Lagopus mutus) in the central Canadian arctic. Arctic 52:23-32.

Cotter, R. C., D. A. Boag, And C. C. Shank. 1992. Raptor predation on Rock Ptarmigan (Lagopus mutus) in the central Canadian arctic. Journal of Raptor Research 26:146-151.

Dimond, W. J. AND D. P. ARMStrong. 2007. Adaptive harvesting of source populations for translocation: a case study with New Zealand Robins. Conservation Biology 21:114-124.

Dinsmore, S. J, G. C. White, And F. L. Knopf. 2002. Advanced techniques for modeling avian nest survival. Ecology 83:3476-3488.

EBbert, S. E. AND G. V. Byrd. 2002. Eradications of invasive species to restore natural biological diversity on Alaska Maritime National Wildlife Refuge. Pages 102-109 in Turning the tide: the eradication of invasive species (C. R. Veitch and M. N. Clout, Editors). IUCN Invasive Species Specialist Group, Gland, Switzerland and Cambridge, United Kingdom.

Emison, W. B. AND C. M. White. 1988. Foods and weights of the Rock Ptarmigan on Amchitka, Aleutian Islands, Alaska. Great Basin Naturalist 48:533-540.

Ewen, J. G. And D. P. Armstrong. 2007. Strategic monitoring of reintroductions in ecological restoration programmes. Ecoscience 14:401-409.

Gardarsson, A. 1988. Cyclic population changes and some related events in Rock Ptarmigan in Iceland. Pages 300-329 in Adaptive strategies and population ecology of northern grouse (A. T. Bergerud and M. W. Gratson, Editors). University of Minnesota Press, Minneapolis, USA.

GiBson, D. D. AND G. V. ByRD. 2007. Birds of the Aleutian Islands, Alaska. Nuttall Ornithological Club and The 
American Ornithologists' Union, Washington, D.C., USA.

Gotelli, N. J. AND A. M. Ellison. 2004. A primer of ecological statistics. Sinauer Associates, Sunderland, Massachusetts, USA.

GRIFFITH, B., J. M. SCOTT, J. W. CARPENTER, AND C. REED. 1989. Translocation as a species conservation tool: status and strategy. Science 245:477-480.

HANNON, S. J. AND K. MARTIN. 2006. Ecology of juvenile grouse during the transition to adulthood. Journal of Zoology 269:422-433.

Hannon, S. J., R. C. GRUys, And J. O. SChIECK. 2003. Differential seasonal mortality of the sexes in Willow Ptarmigan Lagopus lagopus in northern British Columbia, Canada. Wildlife Biology 9:317-326.

HofFMAN, R. W. AND K. M. GIESEN. 1983. Demography of an introduced population of White-tailed Ptarmigan. Canadian Journal of Zoology 61:1758-1764.

Holder, K. AND R. MonTGOMERIE. 1993. Rock Ptarmigan (Lagopus mutus). The birds of North America. Number 51.

Holder, K., R. Montgomerie, And V. L. Friesen. 2000. Glacial vicariance and historical biogeography of Rock Ptarmigan (Lagopus mutus) in the Bering region. Molecular Ecology 9:1265-1278.

Holder, K., R. MontGomerie, And V. L. Friesen. 2004. Genetic diversity and management of Nearctic Rock Ptarmigan (Lagopus mutus). Canadian Journal of Zoology 82:564-575.

JACOBSEn JR., E. E., C. M. White, ANd W. B. EMison. 1983. Molting adaptations of Rock Ptarmigan on Amchitka Island, Alaska. Condor 85:420-426.

JAMIESON, I. G. AND G. C. WILSON. 2003. Immediate and long-term effects of translocations on breeding success in Takahe Porphyrio hochstetteri. Bird Conservation International 13:299-306.

KALER, R. S. A. 2007. Demographic measures, habitat use, and movement of a recently reintroduced island population of Evermann's Rock Ptarmigan. Thesis. Kansas State University, Manhattan, USA.

KLEIN, D. R. 1968. The introduction, increase, and crash of reindeer on St. Matthew Island. Journal of Wildlife Management 32:350-367.

Klett, A. T. And D. H. Johnson. 1982. Variability in nest survival rates and implications to nesting studies. Auk 99:77-87.

KomdeuR, J. 1994. Conserving the Seychelles Warbler Acrocephalus sechellensis by translocation from Cousin Island to the islands of Aride and Cousine. Biological Conservation 67:143-152.

KurZeJESKI, E. W. AND B. G. Root. 1988. Survival of reintroduced Ruffed Grouse in north Missouri. Journal of Wildlife Management 52:248-252.

Major, H. L., I. L. Jones, G. V. Byrd, AND J. C. Williams. 2006. Assessing the effects of introduced Norway rats (Rattus norvegicus) on survival and productivity of Least Auklets (Aethia pusilla). Auk 123:681-694.

Maron, J. L., J. A. Estes, D. A. Croll, E. M. Danner, S. C. Elmendorf, AND S. L. BuCKelew. 2006. An introduced predator alters Aleutian island plant communities by thwarting nutrient subsidies. Ecological Monographs 76:3-24.

MERCER, W. E. 1967. Ecology of an island population of Newfoundland Willow Ptarmigan. Technical Bulletin Number 2. Newfoundland and Labrador Wildlife Service, St. John's, Canada.

Moran, R. J. AND W. L. PAlmer. 1963. Ruffed Grouse introductions and population trends on Michigan islands. Journal of Wildlife Management 27:606-614.

Murie, O. J. 1959. Fauna of the Aleutian Islands and Alaska Peninsula. North American Fauna 61:1-406.

Musil, D. D., J. W. Connelly, And K. P. Reese. 1993. Movements, survival, and reproduction of Sage Grouse translocated into central Idaho. Journal of Wildlife Management 57:85-91.

Novoa, C., A. Besnard, J. F. BREnOt, And L. N. Ellison. 2008. Effect of weather on the reproductive rate of Rock Ptarmigan Lagopus muta in the eastern Pyrenees. Ibis 150:270-278.

Powell, L. A. 2007. Approximating variance of demographic parameters using the delta method: a reference for avian biologists. Condor 109:949-954.

ReEse, K. P. AND J. W. Connelly. 1997. Translocation of Sage Grouse Centrocercus urophasianus in North America. Wildlife Biology 3:235-241.

Reynolds, M. H., N. E. Seavy, M. S. Vekasy, J. L. KlavitTer, AND L. P. Laniawe. 2008. Translocation and early post-release demography of endangered Laysan Teal. Animal Conservation 11:160-168.

RobB, L. A., K. Martin, And S. J. HANnON. 1992. Spring body condition, fecundity and survival in female Willow Ptarmigan. Journal of Animal Ecology 61:215-233.

Robertson, H. A., I. Karika, and E. K. SAul. 2006. Translocation of Rarotonga Monarchs Pomarea dimidiata within the southern Cook Islands. Bird Conservation International 16:197-215.

ROHWER, F. C. 1988. Inter- and intraspecific relationships between egg size and clutch size in waterfowl. Auk 105:161-176.

SANDERCOCK, B. K. 1993. Free-living Willow Ptarmigan are determinate egg-layers. Condor 95:554-558.

SANDERCOCK, B. K. AND H. C. Pedersen. 1994. The effects of renesting ability and nesting attempts on egg-size variation in Willow Ptarmigan. Canadian Journal of Zoology 72:2252-2255.

SANDERCock, B. K., K. MARtin, AND S. J. HANnON. 2005. Life history strategies in extreme environments: comparative demography of arctic and alpine ptarmigan. Ecology 86:2176-2186.

SARRAZIN, F. AND S. Legendre. 2000. Demographic approach to releasing adults versus young in reintroductions. Conservation Biology 14:488-500.

SCHERINI, G. C., G. Tosi, AND L. A. WAUTERS. 2003. Social behaviour, reproductive biology and breeding success of alpine Rock Ptarmigan Lagopus mutus helveticus in northern Italy. Ardea 91:11-23.

SMITH, A. AND T. WILLEBRAND. 1999. Mortality causes and survival rates of hunted and unhunted Willow Grouse. Journal of Wildlife Management 63:722-730.

Snyder, J. W., E. C. Pelren, AND J. A. Crawford. 1999. 
Translocation histories of prairie grouse in the United States. Wildlife Society Bulletin 27:428-432.

Springer, P. F., G. V. Byrd, AND D. W. Woolington.

1977. Reestablishing Aleutian Canada Geese. Pages 331-338 in Endangered birds: management techniques for preserving threatened species (S. A. Temple, Editor). University of Wisconsin Press, Madison, USA.

StAmps, J. A. AND M. BuECHNER. 1985. The territorial defense hypothesis and the ecology of insular vertebrates. Quarterly Review of Biology 60:155-181.

STEEN, J. B. AND S. UNANDER. 1985. Breeding biology of the Svalbard Rock Ptarmigan (Lagopus mutus hyperboreus). Ornis Scandinavica 23:366-370.

WAtson, A. 1965. A population study of ptarmigan (Lagopus mutus) in Scotland. Journal of Animal Ecology 34:135-172.

WeEDEN, R. B. 1965. Breeding density, reproductive success, and mortality of Rock Ptarmigan at Eagle Creek, central Alaska, from 1960 to 1964. Transactions of the North American Wildlife and Natural Resources Conference 30:336-348.

Weeden, R. B. And A. WAtson. 1967. Determining the age of Rock Ptarmigan in Alaska and Scotland. Journal of Wildlife Management 31:825-826.
WestersKov, K. 1950. Methods for determining the age of game bird eggs. Journal of Wildlife Management 14:56-67.

Wiebe, K. L. AND K. Martin. 2000. The use of incubation behavior to adjust avian reproductive costs after egg laying. Behavioral Ecology and Sociobiology 48:463470.

Wiggins, D. A., A. P. Møller, M. F. L. Sørenson, AND L. A. BRAND. 1998. Island biogeography and the reproductive ecology of Great Tits Parus major. Oecologia 115:478-482.

Williams, J. C., G. V. Byrd, and N. B. Konyukhov. 2003. Whiskered Auklets Aethia pygmaea, foxes, humans and how to right a wrong. Marine Ornithology 31:175-180.

Wilson, S., K. Martin, and S. J. Hannon. 2007. Nest survival patterns in Willow Ptarmigan: influence of time, nesting stage, and female characteristics. Condor 109:377-388.

Zimmerman, C. E., N. Hillgruber, S. E. Burril, M. A. St. Peters, AND J. D. WetZEL. 2005. Offshore marine observation of Willow Ptarmigan, including water landings, Kuskokwim Bay, Alaska. Wilson Bulletin 117:12-14. 